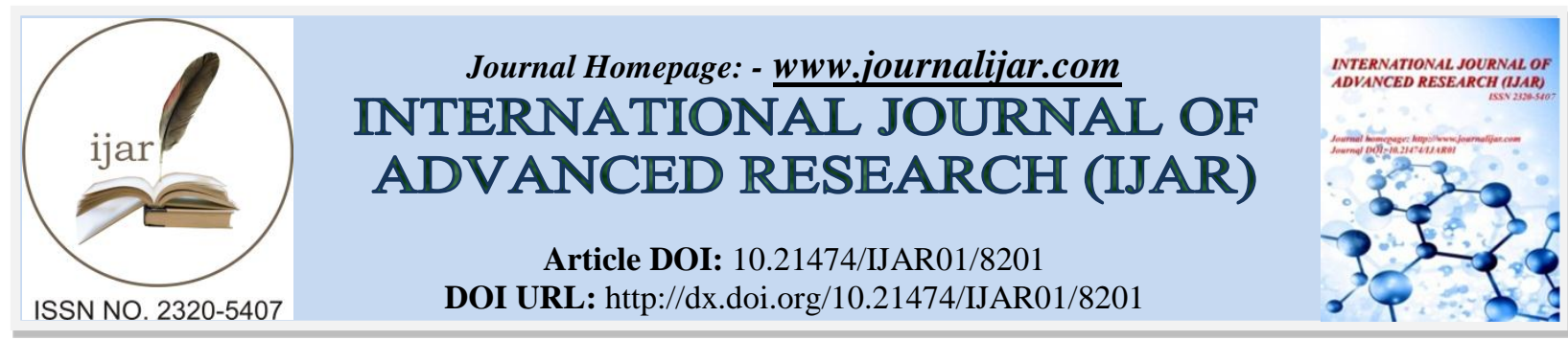

RESEARCH ARTICLE

\title{
RESEARCH ON BUSINESS PERFORMANCE EVALUATION OF POWER GENERATION LISTED COMPANIES BASED ON DEA MODEL.
}

Yan Suli, Yan Wenjing, Lin Xiangmin and Liu Jicheng.

School of Economics and Management, North China Electric Power University, Beijing, China.

\section{Manuscript Info}

\section{Manuscript History}

Received: 12 October 2018

Final Accepted: 14 November 2018

Published: December 2018

Keywords:

DEA, thermal power,new energy power generation, listed company, business performance.

\begin{abstract}
With the global energy transformation and the gradual growth of domestic electricity demand, China's power generation enterprises are facing new challenges. Based on the financial data of 30 listed power generation companies in China, this paper constructs the operating performance evaluation system of power generation companies, measures the comprehensive efficiency, input redundancy rate and output insufficiency rate of listed power generation companies, and compares and analyzes the operating status of listed thermal power and new energy power generation companies.The research shows that the overall operating performance of power generation listed companies is not good, and the rationality of business input and output has a greater room for improvement.
\end{abstract}

Copy Right, IJAR, 2018,. All rights reserved.

\section{Introduction:-}

For a long time, China's thermal power-based power generation has met the growing demand for electricity in various industries. However, due to resource constraints and environmental improvements, the development rate of thermal power has slowed down. As an emerging force, new energy power generation has developed rapidly in recent years. The advancement of technology and the support of policies have provided a good environment for the development of new energy power generation, so that the amount of new energy power generation will increase year by year. In 2017 , new energy power generation increased by $24.6 \%$, much higher than the $5.9 \%$ increase in thermal power. However, there is a certain blindness behind the rapid growth of new energy power generation. The operation status and development speed of new energy power generation companies do not match completely. Therefore, a comparative study of the operating performance of thermal power and new energy power generation listed companies is of great significance for finding the gap between listed companies and promoting healthy development.

Domestic and foreign scholars have carried out various researches on the efficiency of power generation enterprises. Santo (2017) evaluated the benefits of different forms of thermoelectricity using thermal efficiency indicators [1]. Li Shaolin (2016) based on Bootstrap-DEA measured the comprehensive efficiency of new energy generation in 23 countries around the world, and used the tobit regression model to study the driving factors of efficiency [2]. Wang Yanhong and Ye Wenming (2015) measured and decomposed the eco-efficiency of the thermal power industry and explored the relationship between the efficiency of the power industry and the thermal power industry [3]. Lin Li (2017) designed the wind power priority economic dispatch model and energy efficiency model, and studied the

Corresponding Author:-Yan Suli.

Address:-School of Economics and Management, North China Electric Power University, Beijing,

China. 
economics of thermal power plant deep peak shaving [4]. Zhu Zhiwen (2015) used the SBM model and the Malmquist index to compare the environmental performance of thermal power and hydropower enterprises [5].

Domestic and foreign scholars have made great achievements in the efficiency of power generation enterprises, but the research focuses on the efficiency analysis of certain types of power generation in thermal power or new energy power generation. There are few comparative studies on the efficiency of thermal power generation and new energy generation. Therefore, this paper selects 30 domestic listed thermal power and new energy power generation companies as samples, compares and analyzes efficiency differences through data envelopment analysis, and analyzes the situation of input redundancy and output insufficiency, so as to provide ideas for the sustainable development of listed power generation companies in China.

\section{Research Design:- \\ Research Methods}

Data Envelopment Analysis (DEA), proposed by Charnes, Cooper and Rhodes, is a non-parametric method for estimating the relative effectiveness of decision-making units by measuring the ratio of multi-input and multi-output decision-making units [6]. Based on the input-output process of the domestic power generation industry, this paper selects the BCC model with variable scale returns.

There are $\mathrm{m}$ decision-making units, $\mathrm{h}$ input variables, and $\mathrm{l}$ output variables, and the $\mathrm{BCC}$ model is constructed as follows [7]:

$$
\min \left[\theta-\varepsilon\left(\sum_{u=1}^{h} s_{u}^{-}+\sum_{w=1}^{l} s_{w}^{+}\right)\right]\left\{\begin{array}{l}
\sum_{j=1}^{m} \lambda_{j} x_{u j}+s_{u}^{-} \leq \theta x_{u 0}, u=1, \ldots h \\
\sum_{j=1}^{m} \lambda_{j} y_{w j}-s_{w}^{+} \geq y_{w 0}, w=1, \ldots l \\
\sum_{j=1}^{m} \lambda_{j}=1, \\
\lambda_{j} \geq 0, s_{u}^{-} \geq 0, s_{w}^{+} \geq 0, j=1, \ldots, m
\end{array}\right.
$$

Among them, $\varepsilon$ is infinitesimal; $\lambda \mathrm{j}$ is the weight of the $\mathrm{j}$-th decision unit; $\mathrm{u}, \mathrm{w}$ respectively represent the $\mathrm{u}$-th input indicator and the $\mathrm{t}$-th output indicator. $\mathrm{s}_{\mathrm{u}}^{-}, \mathrm{s}_{\mathrm{w}}^{+}$respectively indicate the amount of redundancy of the $\mathrm{u}$-th input indicator and the deficit of the $\mathrm{w}$-th indicator.

If the optimal solution of the model is $\theta^{*}, \lambda^{*}, \mathrm{~s}^{\mathrm{t}^{*}, \mathrm{~s}^{-*}}$, then when $\theta^{*}=1, \mathrm{~s}^{+*}=0$ and $\mathrm{s}^{-*}=0$, DMU is valid for DEA; when $\theta^{*}=1, \mathrm{~s}^{+*} \neq 0$ or $\mathrm{s}^{-*} \neq 0$, DMU is weakly valid for DEA; when $\theta^{*}<1$, DMU is invalid for DEA.

\section{Variable Selection}

Based on the actual production and operation process of power generation enterprises, this paper identifies three input indicators and two output indicators, namely input indicators: total assets, operating costs and period expenses. Among them, the period expense is the sum of management fees, sales expenses and financial expenses. Output indicators: operating income and earnings per share to reflect the results of business activities. The business performance evaluation index system of the power generation listed company is shown in Figure 1. 


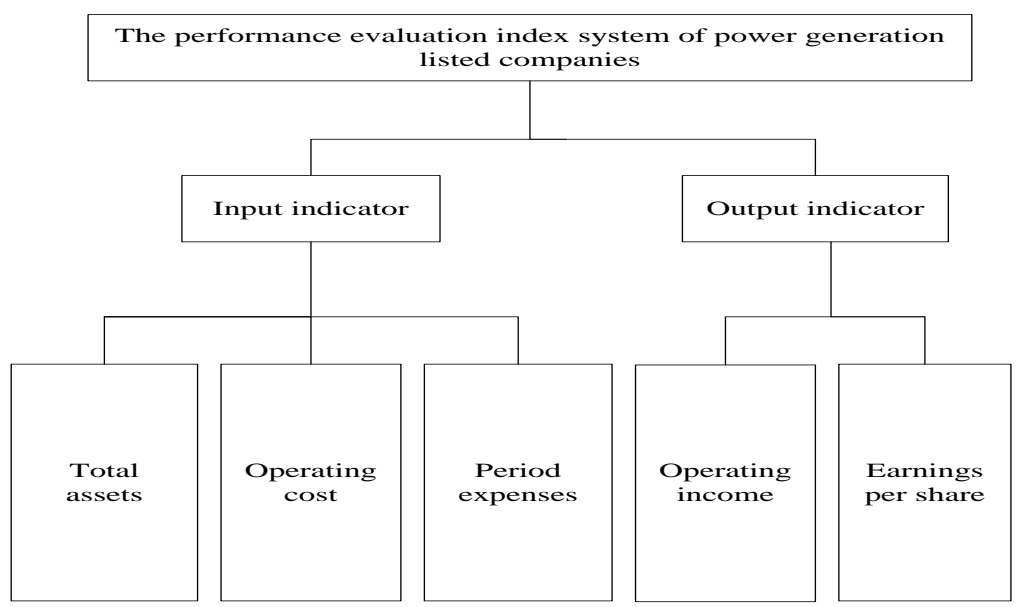

Figure 1:-The performance evaluation index system of power generation listed companies

\section{Sample Selection and Data Source}

This paper selects samples from the concept boards of thermal power, wind power, hydropower and photovoltaic in the flush software and the main business of each power generation listed company in 2015-2017. Excluding the companies with incomplete or abnormal sample data, 30 power generation listed companies were selected. The input and output data selected in this paper are all derived from the annual financial report published by the listed company.

\section{Empirical Analysis:-}

This paper takes 15 thermal power and 15 new energy power generation companies (including 5 wind, 5 solar energy and 5 water) on China's stock exchanges as samples, selects the BCC model with variable scale returns, and analyzes the power generation enterprises with input-oriented. The operating efficiency situation is calculated by using DEAP2.1 software as shown in Table 1, Table 2 and Table 3.

Table 1:-2015-2017 power generation listed company operating efficiency DEA empirical results

\begin{tabular}{|c|c|c|c|c|c|c|c|c|c|}
\hline \multirow[t]{2}{*}{ Type } & \multirow{2}{*}{$\begin{array}{l}\text { Stock } \\
\text { code }\end{array}$} & \multicolumn{3}{|c|}{ Comprehensive efficiency } & \multirow[t]{2}{*}{ Type } & \multirow{2}{*}{$\begin{array}{l}\text { Stock } \\
\text { code }\end{array}$} & \multicolumn{3}{|c|}{ Comprehensive efficiency } \\
\hline & & 2015 & 2016 & 2017 & & & 2015 & 2016 & 2017 \\
\hline \multirow{16}{*}{$\begin{array}{l}\text { Thermal } \\
\text { power }\end{array}$} & 600011 & 0.972 & 0.755 & 0.764 & \multirow[t]{5}{*}{ Wind power } & 000862 & 0.598 & 0.668 & 0.579 \\
\hline & 600021 & 0.841 & 0.561 & 0.561 & & 601016 & 0.781 & 0.717 & 0.802 \\
\hline & 600027 & 1 & 0.665 & 0.715 & & 000690 & 1 & 1 & 0.647 \\
\hline & 600795 & 0.875 & 0.523 & 0.504 & & 600163 & 0.771 & 1 & 1 \\
\hline & 600023 & 0.928 & 0.75 & 0.886 & & 000875 & 0.735 & 0.712 & 0.68 \\
\hline & 600886 & 1 & 0.396 & 0.406 & \multirow[t]{5}{*}{ Hydropower } & 600236 & 1 & 1 & 1 \\
\hline & 600578 & 0.898 & 0.499 & 0.459 & & 600674 & 0.768 & 0.715 & 1 \\
\hline & 000027 & 0.861 & 0.469 & 0.492 & & 000722 & 1 & 1 & 1 \\
\hline & 600098 & 1 & 1 & 1 & & 002039 & 0.981 & 0.793 & 1 \\
\hline & 000543 & 1 & 1 & 1 & & 600900 & 1 & 1 & 1 \\
\hline & 600863 & 0.846 & 0.517 & 0.598 & \multirow[t]{5}{*}{ PV } & 600644 & 1 & 1 & 1 \\
\hline & 000600 & 1 & 1 & 1 & & 000040 & 1 & 1 & 1 \\
\hline & 000539 & 0.926 & 0.693 & 0.734 & & 002256 & 0.989 & 0.792 & 0.816 \\
\hline & 600780 & 1 & 0.737 & 0.814 & & 000591 & 0.767 & 0.804 & 0.788 \\
\hline & 000531 & 1 & 1 & 1 & & 600770 & 0.575 & 0.651 & 0.575 \\
\hline & Average & 0.943 & 0.704 & 0.729 & \multicolumn{2}{|c|}{ New energy average } & 0.864 & 0.857 & 0.859 \\
\hline
\end{tabular}




\section{Efficiency Analysis}

The comprehensive efficiency reflects the overall management level of the company. According to Table 1, the average comprehensive efficiency of thermal power listed companies in 2015 was 0.943 , which was higher than the average comprehensive efficiency of new energy listed companies by 0.864 , indicating that the comprehensive management level of listed companies of thermal power is better than that of new energy listed companies. The average comprehensive efficiency of thermal power listed companies and new energy listed companies showed a trend of decreasing first and then rising, as shown in Figure 2. In 2016, the comprehensive efficiency of thermal power listed companies fell to 0.704 , lower than the comprehensive efficiency of new energy listed companies of 0.857. Although the average comprehensive efficiency of listed thermal power companies increased slightly in 2017, it was still lower than that of listed new energy companies due to the large decline in the previous year. Compared with the stable fluctuation of the average efficiency of new energy listed companies, thermal power listed companies should adjust production and operation activities in time to ensure the relative stability of daily operation and management. Among the three types of new energy listed companies, the average comprehensive efficiency of hydropower listed companies is the highest, which is consistent with the mature development and utilization level of hydropower in China. The average comprehensive efficiency of photovoltaic power generation and wind power listed companies is low, indicating that these two types of power generation listed companies have much room for improvement in the operation and management level.

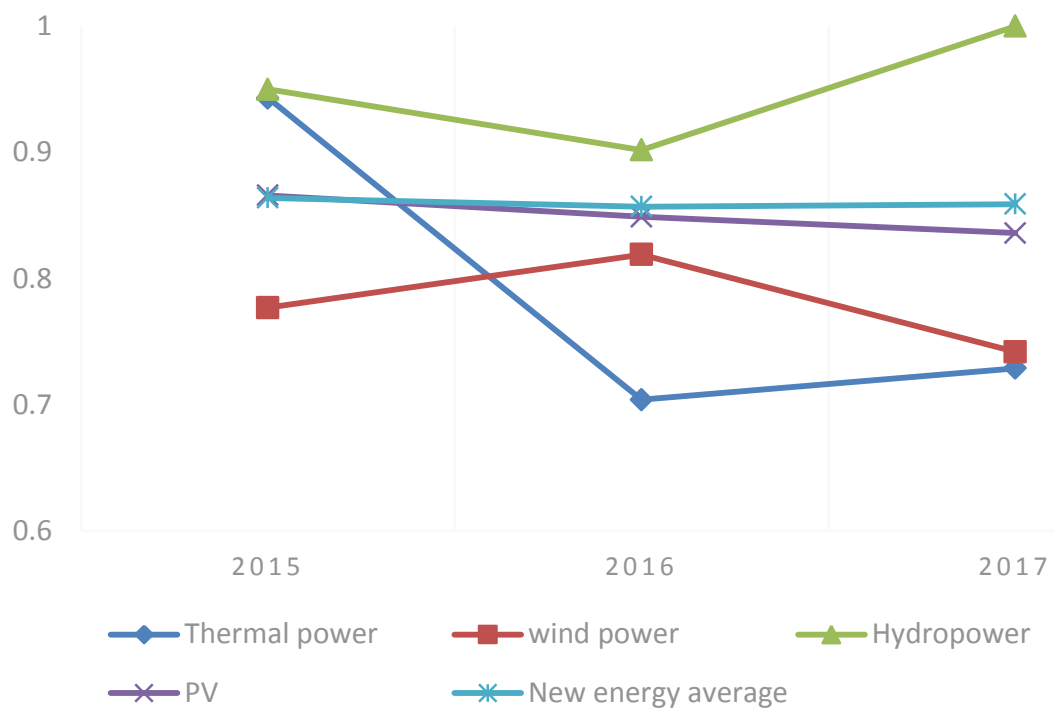

Figure 2:- 2015-2017 power generation listed company comprehensive efficiency trend chart

\section{Projection Analysis}

Table 2 and 3 show the calculation results of the three-year average input redundancy rate and the average output insufficiency rate of power generation listed companies in 2015-2017. Taking Huaneng International (600011) $\mathrm{s}_{1}{ }^{-}$as an example, according to the DEA empirical results, the redundant value of the total assets invested by Huaneng International in 2015 was obtained. Divided by the original input value of the total assets of the year, Huaneng International's 2015 total asset input redundancy rate was obtained. Similarly, we can find the total asset input redundancy ratio of Huaneng International in 2016 and 2017, and calculate the arithmetic mean in the three-year redundancy ratio to obtain the average input redundancy ratio shown in Table 2.

Table 2:-Average input redundancy rate and average output insufficiency rate of thermal power generation listed companies from 2015 to 2017

\begin{tabular}{|l|l|l|l|l|l|l|}
\hline \multirow{2}{*}{ Type } & \multirow{2}{*}{ Stock code } & \multicolumn{3}{|l|}{ Input redundancy rate } & \multicolumn{2}{l|}{ Output insufficiency rate } \\
\cline { 3 - 7 } & & $\mathbf{S}_{\mathbf{1}}^{-}$ & $\mathbf{S}_{\mathbf{2}}{ }^{-}$ & $\mathbf{S}_{\mathbf{3}}^{-}$ & $\mathbf{S}_{\mathbf{1}}{ }^{+}$ & $\mathbf{S}_{\mathbf{2}}{ }^{+}$ \\
\hline \multirow{5}{*}{ Thermal power } & 600011 & 0 & 0 & 0 & 0 & 0 \\
\cline { 2 - 7 } & 600021 & $12.74 \%$ & $12.74 \%$ & $26.34 \%$ & $4.52 \%$ & $26.50 \%$ \\
\cline { 2 - 7 } & 600027 & $6.18 \%$ & $4.73 \%$ & $4.90 \%$ & 0 & $41.76 \%$ \\
\cline { 2 - 7 } & 600795 & $20.44 \%$ & $4.48 \%$ & $4.48 \%$ & $2.74 \%$ & $68.76 \%$ \\
\hline
\end{tabular}




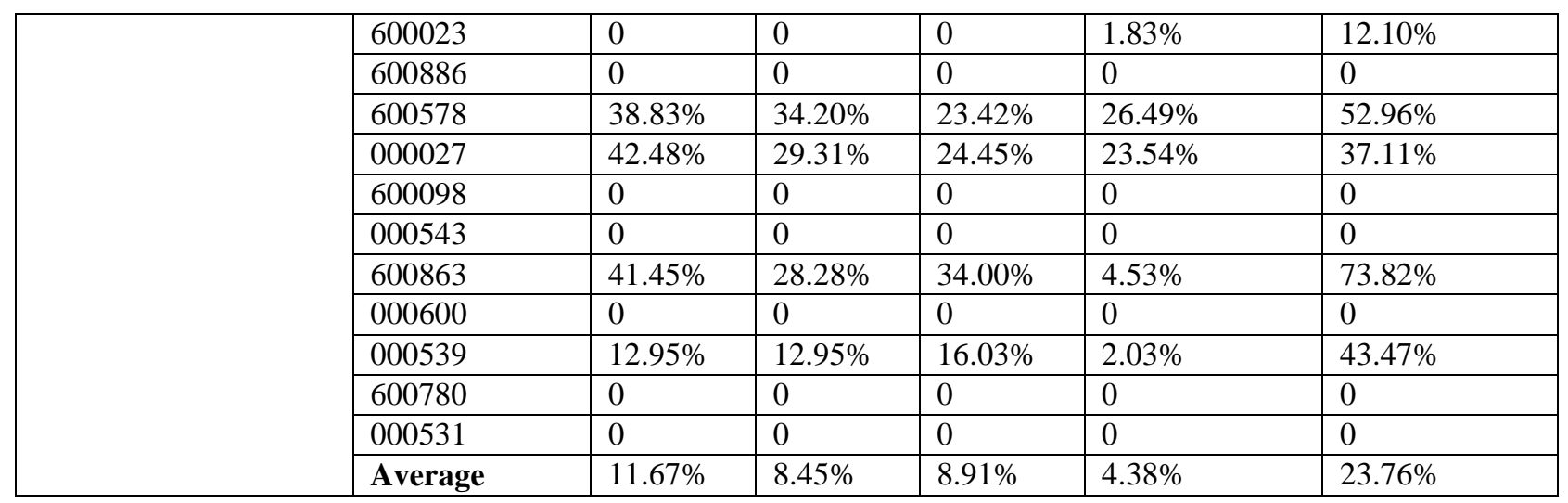

Table 3:-Average input redundancy rate and average output insufficiency rate of new energy power generation listed companies from 2015 to 2017

\begin{tabular}{|c|c|c|c|c|c|c|}
\hline \multirow[t]{2}{*}{ Type } & \multirow[t]{2}{*}{ Stock code } & \multicolumn{3}{|c|}{ Input redundancy rate } & \multicolumn{2}{|c|}{ Output insufficiency rate } \\
\hline & & $S_{1}^{-}$ & $\mathbf{S}_{2}^{-}$ & $\mathbf{S}_{\mathbf{3}}^{-}$ & $\mathrm{S}_{1}^{+}$ & $\mathbf{S}_{2}^{+}$ \\
\hline \multirow{6}{*}{ Wind power } & 000862 & $22.35 \%$ & $22.35 \%$ & $38.56 \%$ & $12.97 \%$ & $95.91 \%$ \\
\hline & 601016 & $31.32 \%$ & $15.33 \%$ & $29.79 \%$ & $6.12 \%$ & $40.19 \%$ \\
\hline & 000690 & $11.13 \%$ & $11.06 \%$ & $11.06 \%$ & $11.44 \%$ & $48.49 \%$ \\
\hline & 600163 & 0 & 0 & 0 & 0 & 0 \\
\hline & 000875 & $19.89 \%$ & $19.89 \%$ & $19.89 \%$ & $15.33 \%$ & $98.89 \%$ \\
\hline & Average & $16.94 \%$ & $13.73 \%$ & $19.86 \%$ & $9.17 \%$ & $56.70 \%$ \\
\hline \multirow[t]{6}{*}{ Hydropower } & 600236 & 0 & 0 & 0 & 0 & 0 \\
\hline & 600674 & 0 & 0 & 0 & 0 & 0 \\
\hline & 000722 & 0 & 0 & 0 & 0 & 0 \\
\hline & 002039 & $3.56 \%$ & $3.56 \%$ & $15.91 \%$ & 0 & 0 \\
\hline & 600900 & 0 & 0 & 0 & 0 & 0 \\
\hline & Average & $0.71 \%$ & $0.71 \%$ & $3.18 \%$ & $0.00 \%$ & $0.00 \%$ \\
\hline \multirow[t]{6}{*}{ PV } & 600644 & 0 & 0 & 0 & 0 & 0 \\
\hline & 000040 & 0 & 0 & 0 & 0 & 0 \\
\hline & 002256 & $6.23 \%$ & $6.23 \%$ & $6.23 \%$ & $4.17 \%$ & $55.84 \%$ \\
\hline & 000591 & $7.72 \%$ & $14.32 \%$ & $7.72 \%$ & $7.07 \%$ & $7.06 \%$ \\
\hline & 600770 & $21.46 \%$ & $21.46 \%$ & $43.87 \%$ & $12.67 \%$ & $77.85 \%$ \\
\hline & Average & $7.08 \%$ & $8.40 \%$ & $11.56 \%$ & $4.78 \%$ & $28.15 \%$ \\
\hline \multicolumn{2}{|c|}{ New energy average } & $8.24 \%$ & $7.61 \%$ & $11.54 \%$ & $4.65 \%$ & $28.28 \%$ \\
\hline
\end{tabular}

Analysis of Input Redundancy

Input redundancy rate refers to the proportion of input that can be saved by dividing the redundancy value of input variable of decision unit with the original input value. It can be seen from Table 2 and Table 3 that whether it is a listed company of thermal power or a listed company of new energy, there is a certain degree of redundancy in the input, and the investment can be appropriately reduced to avoid waste of resources. For thermal power enterprises, the average input redundancy rate of total assets is $11.67 \%$, and the gap between enterprises is large. The maximum value is $42.48 \%$ of Shenzhen Energy (000027). There are 8 enterprises with no investment redundancy, including Huaneng International (600011), Zhe Neng Power (600023), SDIC Power (600886), Guangzhou Development (600098), Wanneng Power (000543), Jiantou Energy (000600), Tongbao Energy (600780) and Sui Hengyun A (000531). For new energy power generation enterprises, the average input redundancy rate during the period is the highest, at $11.54 \%$. There is also a big gap between enterprises. The maximum value is $43.87 \%$ of the Zongyi (600770), and there are 7 enterprises without investment redundancy, namely Zhongmin Energy (600163), Guiguan Power (600236), Sichuan Investment Energy (600674), Hunan Development (000722), Yangtze Power (600900), Leshan Power (600644) and Dongxu Blue Sky (000040). Among them, there are 4 hydropower enterprises, with the most efficient utilization of hydropower resources and the lowest utilization rate of wind power. In general, the redundancy rate of power generation companies' operating costs is relatively small compared to total assets and 
period expenses. In addition, the average input redundancy rate of total assets and operating costs of thermal power listed companies is higher than that of new energy listed companies, and the average input redundancy rate of the period expenses is lower than that of new energy listed companies. On the whole, thermal power and new energy power generation have the same performance in terms of input redundancy, regardless of the advantages and disadvantages.

\section{Analysis of Output Insufficiency}

The output insufficiency rate is the ratio of the output of the decision-making unit that is less than the target output value. As can be seen from Tables 2 and 3, the average output insufficiency rate of operating income is lower, and the average output insufficiency rate of earnings per share is higher. This is mainly due to the low cost of the company and the low net profit of the company, which makes the earnings per share generally low. The highest rate of operating income output of thermal power enterprises is $26.49 \%$ of Jingneng Power (600578), and the highest rate of earnings per share is $73.82 \%$ of Inner Mongolia Huadian (600863).The highest inadequacy ratio of operating income output and earnings per share output of new energy power generation enterprises is the wind power company Jidian shares (000875), which are $15.33 \%$ and $98.89 \%$ respectively. In addition to the wind power business, Jidian also operates thermal power, hydropower, solar power, etc. The low net profit is mainly due to the low power generation hours in the Jilin Province power market and the rising coal market price, so that its thermal power business has caused a lot of profit reduction to the enterprise. Therefore, on the whole, the average output insufficiency rate of new energy power generation enterprises is slightly higher than that of thermal power enterprises. Among them, hydropower enterprises have excellent performance, and none of the five listed companies in the sample has the phenomenon of output insufficiency, while the average output insufficiency rate of wind power enterprises per share exceeds $50 \%$, and their performance is inferior to that of hydropower and photovoltaic power generation enterprises.

\section{Conclusion:-}

Based on DEA, this paper studies the comprehensive efficiency of thermal power and new energy listed companies. The research results show that the comprehensive efficiency of power generation industry in 2015-2017 is not effective, and the rationality of operation input and output has much room for improvement. For thermal power enterprises, the average input redundancy rate of total assets is the highest, while for new energy power generation enterprises, the average input redundancy rate of period costs is the highest. The two can start from reducing the total assets and period expenses to improve the efficiency of resource utilization.

\section{Acknowledge:-}

This research was funded by National Natural Science Foundation of China (Grant NO. 71771085).

\section{References:-}

1. Santo, DBDE, Gallo, WLR .Utilizing primary energy savings and exergy destruction to compare centralized thermal plants and cogeneration/trigeneration systems [J]. Energy, 2017(120): 785-795.

2. Li Shaolin. Estimation and Driving Factors of New Energy Generation Efficiency in 23 Countries in the World from 2001 to 2012[J]. Resources Science, 2016 (02): 321-332.

3. Wang Yanhong, Ye Wenming. Empirical Analysis of Ecological Efficiency of Power Industry and Thermal Power Industry Considering Carbon Emissions (2001-2011)[J].Science and Technology Management Research,2015(03):215-219.

4. Lin Li, Zou Lanqing, Zhou Peng, Tian Xinyu. Multi-angle economic analysis of thermal power plant deep peak shaving under grid-connected wind power conditions[J]. Automation of Electric Power Systems, 2017(07): 2127.

5. Zhu Zhiwen. Environmental Performance Evaluation of China's Electric Power Listed Companies (2011 2013)—_Based on SBM Model Considering Unexpected Output[J].Industrial Technology \& Economy, 2015(10):83-90.

6. Charnes A., Cooper W., Rhodes E. Measuring the Efficiency of Decision Making Units [J]. European Journal of Operations Research, 1978(02): 429-444.

7. Liu Jicheng, Yan Wenjing, Yan Suli. Evaluation of Business Performance of Listed Companies in Wind Power Equipment Manufacturing Industry Based on DEA[J]. Finance and Accounting News, 2018(20): 42-46. 